\title{
A CRÍTICA DO PROGRESSO E DO TRABALHO PRECÁRIO EM LA VITA AGRA, DE LUCIANO BIANCIARDI
}

\section{THE CRITIQUE OF PROGRESS AND PRECARIOUS WORK IN LA VITA $A G R A$, BY LUCIANO BIANCIARDI}

\author{
Ana Maria Chiarini \\ Universidade Federal de Minas Gerais, Belo Horizonte, Minas Gerais, Brasil \\ anachiarini@gmail.com
}

\begin{abstract}
Resumo: La vita agra, romance de forte caráter autobiográfico de Luciano Bianciardi, publicado pela Rizzoli em 1962, pode ser caracterizado como uma crítica contundente ao milagre econômico italiano, a bem-sucedida recuperação do pós-guerra em curso nos anos Cinquenta e Sessenta na Itália. O narrador, que se muda para Milão com a missão terrorista de vingar quarenta e três trabalhadores mortos em uma mina de carvão e acaba se tornando um tradutor, tem muito a dizer sobre o mundo do trabalho, o consumo e as relações pessoais numa grande cidade. Este texto se propõe a alinhar o romance à crítica do progresso, em particular, a Walter Benjamin, e a evidenciar sua análise precursora da precarização do trabalho nas últimas décadas.
\end{abstract}

Palavras-chave: Luciano Bianciardi; Progresso; Trabalho Precário

\begin{abstract}
La vita agra, intensely autobiographical novel by Luciano Bianciardi, published by Rizzoli in 1962, may be described as a scathing critique of the Italian economic miracle, the successful postwar recovery underway in the 1950s and 1960s in Italy. The narrator, who moves to Milan on a terrorist mission to avenge the death of forty-three coal miners and ends up becoming a translator, has a lot to say about labour, consumption and personal relationship in a big city. This article aims at aligning this novel with the critique of progress, especially Walter Benjamin's theorizations, and highlighting its predictive analysis of precarious work in recent decades.
\end{abstract}

Keywords: Luciano Bianciardi; Progress; Precarious work 
Certamente bem menos conhecido do que outros escritores a ele muito próximos na linha temporal, - Italo Calvino, nascido em 1922, Leonardo Sciascia, em 1921, e Pier Paolo Pasolini, em 1923 -, Luciano Bianciardi (1922-1971) tem presença definitiva na literatura e na crítica cultural italiana do século XX, sendo, inclusive, objeto de atenção entusiasmada por parte de jovens leitores e autores contemporâneos. Como apontam diversos estudiosos que se debruçaram sobre sua obra e como bem resume Gian Paolo Serino,

Bianciardi foi o primeiro romancista e ensaísta, bem antes de Umberto Eco e Pier Paolo Pasolini, a intuir - e a escrever - como a sociedade de consumo é apenas uma ilusão [...] Através de seus romances, artigos, através de suas mais de cem traduções dos mais importantes escritores americanos. Bianciardi foi o primeiro a descrever como, num mundo que continua a progredir, ninguém, na verdade, progride. $(\text { SERINO, 2015, p. 21,22) })^{12}$

É sempre arriscado afirmar que tal nome tenha sido o primeiro em determinado campo, mas parece haver consenso por parte dos especialistas no Novecento italiano de que Bianciardi antecipa, com profundidade e irreverência, as reflexões de Pier Paolo Pasolini e as de Umberto Eco, fundamentais para desmontar o milagre econômico do pós-guerra, a Itália dele resultante, bem como as modas e vícios da cultura de massa que vinha se consolidando. Aquilo que Pasolini denuncia ${ }^{3}$, buscando ler as consequências, sobretudo, políticas na década de Setenta, como o fenômeno "fulmíneo e fulgurante" do "desaparecimento dos vaga-lumes"4 (PASOLINI, 1975), ocorrido no início dos anos Sessenta, já era tematizado em La vita agra, narrativa bianciardiana de 1962 e foco do presente texto. O italiano médio, socializado e reconfortado pela televisão, cujo ídolo era o apresentador Mike Bongiorno, exemplar em sua mediocridade, segundo um famoso texto de $\mathrm{Eco}^{5}$, também transita pelas ruas simultaneamente lúgubres e frenéticas do mesmo romance.

Ao descrever os clientes no supermercado, uma novidade na época, pois o primeiro estabelecimento do gênero na Itália abre as portas em 1957, o narrador sugere zumbis criaturas de pupilas dilatadas, graças às cores e às luzes, que "não batem mais as pálpebras, não enxergam você" (BIANCIARDI, 2016, p. 172) e que, "ceg[a]s como estão[,] comprariam"6 (BIANCIARDI, 2016, p. 174) até livros, se estes lhe fossem oferecidos. Ao se referir aos trabalhadores que transitam pelo centro da cidade, é igualmente cáustico:

Você não encontra pessoas, apenas a imagem delas, o seu espectro, os invólucros, os invasores de corpos, os ectoplasmas. Nos primeiros meses de sua chegada à cidade, talvez não, talvez resistam e tenham ainda uma consistência física, mas basta um meio ano para que se esvaziem por dentro, percam a linfa e o sangue, se tornem cascas. (BIANCIARDI, 2016, p. 196). ${ }^{7}$

\footnotetext{
${ }^{1}$ Uma vez que La vita agra nunca foi publicado no Brasil, todas as passagens do romance aqui citadas foram traduzidas por mim, assim como os excertos dos outros textos que não se encontram em português na bibliografia.

${ }^{2}$ Bianciardi è stato il primo romanziere e saggista, bem prima di Umberto Eco e di Pier Paolo Pasolini, a intuire - e scrivere - come la società dei consumi sia soltanto una mera illusione. [...] Attraverso i suoi romanzi, i suoi saggi, i suoi articoli, attraverso le sue oltre cento traduzioni dai più importanti scrittori americani. Bianciardi descrisse per primo come in un mondo che continua a progredire come nessuno progredisce veramente.

3 "Il vuoto del potere" ovvero "l'articolo delle lucciole" é o nome desse artigo específico, que foi publicado originalmente no Corriere della Sera em 01.02.1975 e reproposto na coletânea póstuma Scritti corsari, de 1975. 4 "fulmineo e folgorante"; "scomparsa delle lucciole"

5 O ensaio Fenomenologia di Mike Bongiorno compõe Diario Minimo, de 1963, e se baseia em Mike: l'elogio della mediocrità, artigo proposto em 29.07.1959, no jornal Avanti.

6 "non battono più le palpebre, non ti vedono"; "accecati come sono comprerebbero [anche quelli]".

7 Non trovi le persone, ma soltanto la loro immagine, il loro spettro, trovi i baccelloni, gli ultracorpi, gli ectoplasmi. Nei primi mesi del loro arrivo in città forse no, forse resistono e hanno ancora una consistenza fisica, ma basta un mezzo anno perché si vuotino dentro, perdano linfa e sangue, diventino gusci.
} 
Esse palco da desumanização, deflagrada em nome da eficiência e do progresso, e um dos alvos da raiva ${ }^{8}$ do narrador-protagonista, bem como de nosso autor provinciano, é Milão. Deixando para trás esposa e filha, Bianciardi mudou-se de Grosseto, na Toscana, para a metrópole do norte do país, em 1954, onde trabalhou como redator na nascente editora Feltrinelli e, em seguida, como tradutor autônomo, profissão que viria a exercer até a morte, provocada pelo álcool e pela cirrose, aos 49 anos. Ali escreveu seus textos narrativos apenas aos domingos, pois, durante a semana, traduzia nomes importantes, como Henry Miller, William Faulkner, Saul Bellow e John Steinbeck, além de textos de divulgação e manuais técnicos, na companhia - e, muitas vezes, com parceria - de Maria Jatosti, poeta e mãe de um de seus filhos. Já o narrador anônimo de La vita agra transfere-se para Milão com a missão terrorista de explodir a sede da indústria química responsável pela morte de 43 trabalhadores em uma mina de carvão nas imediações de Grosseto. Em princípio, sua intenção é aceitar o emprego que lhe permita sobreviver e manter a esposa e o filho na província, enquanto espera a ocasião para o grande ataque, ocasião esta que, porém, nunca se apresenta. Assim, dentro de sua casa em Milão, entre laudas a serem traduzidas e cálculos para conseguir chegar ao final do mês, do mesmo modo que o escritor, na vida real, ele vive e trabalha com a nova companheira durante os anos do milagre econômico italiano.

É útil esclarecer que, quando ainda exercia a função de bibliotecário na cidade natal, Bianciardi havia escrito, com o amigo e escritor Carlo Cassola, I minatori della Maremma [Os mineiros da Maremma ${ }^{9}$ ], um documento de denúncia, produto de um notável trabalho investigativo na mesma área de extração de carvão que logo ocuparia o noticiário nacional e as páginas de La vita agra. A tragédia na mina, tão importante para o autor e para o personagem, além de confirmar o caráter autoficcional da narrativa, é exatamente o que desencadeia sua implacável crítica ao componente farsesco, grávido de crimes, do progresso no período.

O comentário do narrador sobre uma de suas caminhadas diárias tece uma remissão significativa na obra:

\footnotetext{
Mas não é um passeio. É muito mais uma marcha, arrítmica e curvada, com sapatos hegelianos que machucam, o vento sempre no rosto, quando sopra, e a garoa que pinga no pescoço, ou o sol nos olhos, e continuamente a tensão de ter de vigiar o trânsito, mesmo na calçada, porque não é raro que os carros invadam também o terreno dos pedestres, e os esmaguem. (BIANCIARDI, 2016, p. 177). ${ }^{10}$
}

Se considerarmos que os estudiosos situam o nascimento da ideologia do progresso no Iluminismo, tendo o ápice em Hegel, sua "suprema expressão filosófica" (LÖWY; VARIKAS, 1992, p. 201), é fácil compreender que a "marcha, arrítmica e curvada, com sapatos hegelianos que machucam" é uma referência crítica à concepção de história como marcha em direção à liberdade proposta pelo pensador alemão. No quadro que se desenha no romance, na cidade cinza onde o crescimento da produção é o que conta, de escassa liberdade gozam os habitantes transformados em robôs e o trabalhador informal que, a despeito de estar à margem do sistema, obedece ritmos industriais para sobreviver. Como observa Bianciardi, a caminhada é forçada, profundamente desconfortável, em nada semelhante a um passeio; ao contrário, traz sofrimento para o corpo e para a mente e, no limite, pode ser fatal.

Domenico Losurdo, em Hegel e a liberdade dos modernos, defende o filósofo e sua

8 La vita agra, juntamente a Il lavoro culturale, de 1957, e L'integrazione, de 1960, três narrativas de marcada carga autobiográfica, formam a chamada "trilogia da raiva" bianciardiana.

9 Região geográfica que compreende parte do Lácio e da Toscana e se debruça sobre o Mar Tirreno.

$10 \mathrm{Ma}$ non è una passeggiata. Piuttosto è una marcia, aritmica e aggobbita, con le scarpe hegeliane che fanno male, il vento sempre in faccia quando c'è, e la pioggerella che gocciola sul collo, o il sole negli occhi, e di continuo la tensione di dover badare al traffico, anche stando sul marciapiede, perché non è raro che le macchine invadano anche la sede pedonale, e ti schiaccino. 
crença na racionalidade de um processo histórico que avança como francamente democráticos. Segundo Losurdo, todo o pensamento do alemão, ancorado nos conflitos e convulsões sociais da época, em especial, na Revolução Francesa, reconhece a irreversibilidade do processo histórico, entre outros motivos, porque a humanidade, percebendo-se enquanto tal, não mais permitiria que lhe tomassem a dignidade conquistada com a luta política. Para Hegel, a própria construção da categoria abstrata de "humanidade" seria já resultado de um notável progresso, o que viria a se manifestar também no "avanço da formalidade jurídica que substitui o empenho reconfortante exclusivamente diante da palavra dada e, sobretudo, pelo fato de que a beneficência se torna supérflua" (LOSURDO, 2019, p. 332). Liberdade, igual dignidade e autonomia são direitos inalienáveis de todos, resultantes de um longo e turbulento processo histórico, afirmados pelo pensamento corajoso do filósofo conclui Losurdo -, que desafia a ideia de natureza como reino do domínio do mais forte, privilegiada pelos ideólogos contrarrevolucionários de seu tempo.

Mas os tempos de La vita agra são outros. É sintomático que o romance tenha sido publicado no ano que Theodor Adorno fez a famosa conferência intitulada Progresso, concentrando-se no conceito que "resiste ainda menos que outros à exigência de especificação daquilo a que realmente se refere, como na pergunta sobre o que progride e o que não" (ADORNO, 1992, p. 217). Embora não pareça existir nenhuma evidência de que Luciano Bianciardi, intelectual e leitor sofisticado, tivesse algum tipo de familiaridade com a produção de Adorno ou de seu amigo e inspirador Walter Benjamin, tampouco parece estranha a descrença numa razão que traça caminhos sem retrocessos para a sociedade do século XX, que, segundo Hobsbawn (1997, p. 16), "foi de calamidade em calamidade" por quarenta anos e, em determinadas ocasiões, "mesmo conservadores inteligentes não apostariam em sua sobrevivência”. Löwy e Varikas (1992) também advertem que a crítica ocidental do progresso não é nova, deitando suas raízes no romantismo alemão do final do século XVIII, num forte contraponto à voz hegeliana, com ecos críticos diversos.

No romance, o progresso manifesta-se à luz de um "fenômeno identificado, preciso e etiquetado"11 (BIANCIARDI, 2016, p. 158): o milagre italiano. Tal milagre, ilusório, excludente, forjado na exploração capitalista, de um lado, e na acomodação e passividade, de outro, é impulsionado por muitos no dia a dia urbano: além dos consumidores zumbis, há aqueles que cuidam para que toda a máquina da produção funcione sem entraves funcionários em ascensão na carreira, contadores, secretárias assexuadas, caminhando, ou marchando, de salto alto - e aqueles como Vittorio, homem plácido, que, atrás de um volante, "fechado numa caixa de rancor", transforma-se numa fera e crê que, dentro do carro, seja capaz de alargar "seu círculo de liberdade objetiva, de ser homem livre desde o Duomo até o mar"12 (BIANCIARDI, 2016, p. 168). O exército de milaneses em marcha para o futuro, como era de se esperar, também tem baixas e desertores, soldados, talvez, menos significativos para o avanço das tropas: o bêbado caído na rua, sob a indiferença dos passantes, os mortos "por vocação suicida, por vício absurdo"13 (BIANCIARDI, 2016, p. 155) - como Marina, cujo ato é ocultado de todos, e Remo, descoberto por uma funcionária da empresa em casa, após três dias de "ausência injustificada que prejudicava as vendas"14 (BIANCIARDI, 2016, p. 155) -, ou ainda os mortos em abandono, como Enzo, "um vampiro também ele"15 (BIANCIARDI, 2016, p. 156), apesar de sociável e sedento de convívio, consideradas suas inúmeras e necessárias transfusões de sangue.

11 "fenomeno individuato, preciso ed etichettato"

12 "chiuso in una scatola di rancore"; "la sua cerchia di libertà oggettiva, di essere uomo libero da piazza del Duomo fino al mare [della foce]"

13 "per vocazione suicida, per vizio assurdo"

14 "assenza ingiustificata che danneggiava le vendite"

15 "un vampiro anche lui" 
Esse panorama metropolitano, de egoísmo e solidão, em nada se assemelha à cena idílica enraizada no catolicismo, presente na formação do escritor e no passado do personagem, que é usualmente associada ao termo "milagre":

Todos esses são sintomas, vistos em negativo, de um fenômeno que a maioria chama de milagroso, esquecendo [...] que os milagres verdadeiros acontecem quando se multiplicam pães, peixes e vasos de vinho, e as pessoas, todas juntas, comem grátis e bebem [...] Comem e bebem em companhia na relva, em grupos de cem e de cinquenta. Comem, bebem e cantam, escutam a palestra e, assim que escurece, sempre ali, na relva, como dá, fazem amor. O palestrante já se retirou com os seus doze assistentes e com eles conversa, sorrindo. É um doutorzinho judeu, louro, de uns trinta anos. (BIANCIARDI, 2016, p. 159). ${ }^{16}$

O milagre italiano decerto levanta todas as suspeitas sobre "o que progride e o que não" da advertência de Adorno. Nele estão presentes o desenvolvimento tecnológico e da ciência, a evolução da comunicação e a formalização das relações trabalhistas, mas também o declínio moral e a desumanização. Poucas perspectivas promissoras são apresentadas por Bianciardi nessa dialética do progresso, e alguns agentes supostamente cruciais para uma mudança real aparecem em vestes ridículas nas páginas da narrativa, como o intelectual obcecado com a superação do neorrealismo no cinema italiano ou a célula do partido comunista que funciona num salão de beleza para cães. A explicação do narrador do que seria, na verdade, a famosa névoa de Milão, elevando-a à condição de alegoria, remete a outra visão famosa e profundamente pessimista da modernidade, da qual um anjo, escombros e uma tempestade fazem parte.

Eles a chamam de névoa [...], vangloriam-se dela como de um produto local. E produto local é. Só isso, não é névoa. [...]

Quando muito, é uma fumigação raivosa, uma flatulência de homens, motores, chaminés, é suor, é chulé, poeirão erguido pelos saltos dos sapatos das secretárias, das putas, dos representantes, dos gráficos, dos relações públicas, das estenodatilógrafas, é hálito de dentes podres, de estômagos ulcerados, de intestinos congestionados, de esfíncteres apertados, é fedor de axilas desodorizadas, de bocetas ociosas, de paus inativos. (BIANCIARDI, 2016, p. 168,169). ${ }^{17}$

Se na IX Tese de Benjamin, o Anjo da História, olhando para trás, enxerga escombros e é impelido para o futuro pela tempestade do progresso, nesse excerto de La vita agra, exalando mau cheiro e produzindo poeira, reaparecem os sapatos em marcha, observados pelo narrador desajustado, sempre à margem, que, em outro momento da narrativa, havia sido demitido "apenas devido ao fato de que arrasto os pés, me movo lentamente, olho em volta mesmo quando não é indispensável"18 (BIANCIARDI, 2016, p. 110). Enquanto Benjamin nos propõe uma cena ocupada por mortos amontoados e um anjo

16 Tutti questi sono i sintomi, visti al negativo, di un fenomeno che i più chiamano miracoloso, scordando [...] che i miracoli veri sono quando si moltiplicano pani e pesci e pile di vino, e la gente mangia gratis tutta insieme, e beve [...]. Mangiano e bevono a brigate sull'erba, per gruppi di cento e di cinquanta. Mangiano, bevono e cantano, stanno a sentire la conferenza e appena buio, sempre lì sull'erba, come capita capita, fanno all'amore. Il conferenziere si è tirato in disparte coi suoi dodici assistenti, e discorre con loro sorridendo. È un dottorino ebreo, biondo, sui trent'anni.

17 La chiamano nebbia [...], se ne gloriano come di un prodotto locale. E prodotto locale è. Solo, non è nebbia. [...] È semmai una fumigazione rabbiosa, una flatulenza di uomini, di motori, di camini, è sudore, è puzzo di piedi, polverone sollevato dal taccheggiare delle segretarie, delle puttane, dei rappresentanti, dei grafici, dei PRM, delle stenodattilo, è fiato di denti guasti, di stomachi ulcerati, di budella intasate, di sfinteri stitici, è fetore di ascelle deodorate, di sorche sfitte, di bischeri disoccupati.

18 "soltanto per via di questo fatto che strascico i piedi, mi muovo piano, mi guardo attorno anche quando non è indispensabile" 
impedido de se deter frente à dor, Bianciardi nos apresenta o olhar do narrador sobre criaturas atormentadas e desconfortáveis dentro dos próprios corpos na Milão da eficiência do trabalho. Convém ressaltar que ambos, Benjamin e Bianciardi, compartilham de total descrença naquilo que impulsiona o movimento.

Diante do nazismo e da barbárie da Segunda Guerra, Benjamin produz um repúdio, dos mais incisivos, do conceito de progresso, atacando-o em várias frentes: "o evolucionismo darwinista, o determinista de tipo científico-natural, o otimismo cego - dogma da vitória 'inevitável' do partido - e a convicção de 'nadar no sentido da corrente' (o desenvolvimento técnico)" (LÖWY, 2002, p. 205). No centro de sua filosofia, em confronto, estabelece a categoria de catástrofe. Já o escritor Bianciardi, servindo-se de sua revolta pessoal, desencadeada por uma tragédia - os 43 mineiros mortos na província de Grosseto ${ }^{19}$-, num jogo com seu narrador e alter ego, constrói uma poderosíssima crítica ao progresso em sua face italiana, ou seja, o boom econômico que se inicia no final dos anos Cinquenta Com a poeira erguida pelos sapatos no grande canteiro de obras em que Milão se transformara após os bombardeios e o período fascista, salta aos olhos do leitor a poeira asfixiante da explosão da mina de Ribolla. Michael Löwy esclarece que escovar a história a contrapelo, tarefa do materialista histórico proposta por Benjamin, "significa [...] a recusa em se juntar [...] ao cortejo triunfal que continua, ainda hoje, a marchar sobre aqueles que jazem por terra" (LÖWY, 2005, p. 73). La vita agra também expressa a recusa em aceitar tal cortejo e tal marcha: no frenesi desenvolvimentista da metrópole, onde "tudo aquilo que há de médio aumentou" 20 - a produção, a renda, a idade, a estatura, o consumo de frangos, o número de carros -, a imagem da poeira dos sapatos sugere que "o ocorrido encontra o agora num lampejo" (BENJAMIN, 2007, p. 504), trazendo à tona o trabalho duro e as mortes dos mineiros e reforçando assim, benjaminianamente, sua denúncia.

Cabe dizer que se Bianciardi é capaz de "colher as metamorfoses da época sem perder o olhar de quem se sente um homem qualquer entre os homens" ${ }^{21}$, como aponta Marchesini (2018, p. 9), e antecipa a percepção de um sofrimento já em curso, ainda não tematizado no contexto italiano, há outra faceta crítica do autor que, ao remeter a dinâmicas sociais intensificadas apenas nas últimas décadas, parece ter contribuído para renovar o entusiasmo de uma nova geração de intelectuais e escritores por sua obra ${ }^{22}$ : trata-se de uma análise surpreendentemente arguta e profética da informalidade do trabalho.

Como sabemos, o narrador muda-se para Milão numa solitária, nunca concretizada, missão terrorista, mas se vê obrigado a aceitar um emprego - de início numa editora, depois numa revista de cinema. Definitivamente não talhado para as oito horas diárias em ambiente compartilhado com chefes e colegas, seguindo regras e códigos que despreza, acaba preferindo o trabalho em casa, onde se vê dono do próprio espaço e do próprio tempo, com o auxílio da companheira, na máquina de escrever.

Era possível fazer quinze, até vinte laudas por dia. [...] E sem ter de pegar o bonde, sem precisar se relacionar com o próximo, exceto no final do mês para a entrega do serviço. Podíamos ficar tranquilos em casa, trabalhar juntos de manhã até a noite, em perfeita harmonia, sem medo de demissão, de secretárias ativistas, ou de gerentes em ascensão na carreira. (BIANCIARDI, 2016, p. 131). ${ }^{23}$

19Pino Corrias (2011), em importante biografia do escritor, recolhe depoimentos vários que apontam para o acontecimento trágico como o momento de guinada na vida de Bianciardi em todas as esferas.

20 "[t]utto quello che c'è di medio è aumentato"

21 “cogliere la metamorfosi dell'epoca senza perdere lo sguardo di chi si sente un uomo qualunque tra gli uomini"

22 Bruni (2014) apresenta uma série de obras posteriores a 2000 que são explicitamente inspiradas em La vita agra e no autor grossetano.

23 Riuscivamo a fare anche quindici, anche venti cartelle al giorno [...] E senza bisogno di prendere il tram, senza bisogno di tenere rapporti col prossimo, tranne che alla fine del mese per la consegna del lavoro. Potevamo 
Sem dúvida, regalias do trabalho autônomo. Privilégios, talvez, até os dias de hoje, nomeados, com as devidas atualizações, quando se mencionam os trabalhadores informais e os microempreendedores individuais.

Mas o tradutor faz contas, é forçado a calcular incessantemente e, mesmo crítico ao sistema, contrário a qualquer tipo de colaboração, seu isolamento é relativo. Apesar de distante da subordinação a um superior hierárquico, passa agora a submeter-se ao controle da funcionária da editora, que fiscaliza sua fidelidade ao texto e reprova suas locuções dialetais, deve lidar com os revisores, "indivíduos desconhecidos para você e profissionais da revisão, interessados, portanto, em rever o mais que puderem" 24 , e com a operosidade das secretárias, que verificam o número de caracteres das laudas e descontam dos diálogos, pois, afinal, "você não pode ter a pretensão de que paguem como linha um simples 'sim' de resposta" 25 (BIANCIARDI, 2016, p. 134,135). No regime de trabalho doméstico, precisa sujeitar-se aos contratos com datas implacáveis e multas, aos telefonemas do escritório, cobrando antes do prazo, além de considerar o custo da calefação no inverno rigoroso e do desgaste e das fitas da máquina de escrever. Sem vínculos empregatícios, tem de pesar a impossibilidade de recusar um trabalho, pois outro profissional provavelmente não irá recusá-lo, bem como o duplo azar de adoecer, o que implica gastos com médico e remédios, e queda na produção.

Quanto a essa contabilidade rigorosa, o narrador pondera:

Os melhores eram os livros de quinhentas, seiscentas páginas, que, concluídos em um mês, entregam de uma vez todo o tesouro, que você administra como quiser. Assim, pagas as contas fixas, você fica tranquilo pelo mês inteiro e trabalha de manhã à noite, na santa paz, para pagar as contas fixas do mês seguinte. Sem falar da vantagem de continuar por quatro semanas com o mesmo autor e, vencidas as primeiras cinquenta laudas, se você for esperto, já assimilou o estilo e o léxico, e quase não precisa usar dicionário, o que toma muito tempo. (BIANCIARDI, 2016, p. $137,138){ }^{26}$

Ele descreve uma rotina de ritmos regulares e febris, de tarefas calculadas e imersão completa, apesar das pausas para o sono e repouso incontornáveis: "Toda manhã recomeço como se tivesse parado há dez minutos porque, na verdade, o cérebro nunca parou" 27 (BIANCIARDI, 2016, p. 181). Por volta da uma da tarde, o tradutor, aspirante a terrorista, toma meio litro de leite quente com chocolate e muito açúcar, para prosseguir, cheio de energia, pela "série tortuosa de subordinadas, apositivas, elípticas, como trem quando se depara com um emaranhado de trilhos e avança certeiro até a estação"28 (BIANCIARDI, 2016, p. 183). No correr das horas, chegam as crises de cansaço e as dores, pois "não parece,

starcene tranquilli in casa nostra, lavorare vicini dalla mattina alla sera, in buona armonia, senza timore di licenziamenti, né di segretarie attiviste, né di dirigenti in ascesa.

24 "individui a te ignoti e professionisti del rivedere, interessati perciò a rivedere quanto più possano"

25 "non puoi pretendere che ti paghino come rigo un semplice sì di risposta"

26 Meglio di tutti erano i libri sulle cinque, seicento pagine, che finiti in un mese ti danno il malloppo tutto intero, da sterzare a tuo piacimento. Così, una volta pagati i conti fissi, stai tranquillo per tutto il mese e lavori dalla mattina alla sera in santa pace per pagare i conti fissi del mese prossimo. E poi c'è anche il vantaggio di tirare avanti quattro settimane sempre con lo stesso autore, e passate le prime cinquanta cartelle, se sei accorto, hai assimilato lo stile e il lessico, e quasi non c'è più nemmeno bisogno di ricorrere al vocabolario, che porta via parecchio tempo.

27 "Ogni mattina io riattacco come se avessi smesso dieci minuti prima, perché il cervello in realtà non si è mai arrestato"

28 "serie tortuosa delle subordinate, degli incisi, delle ellittiche, come un treno quando affronta un groviglio di binari e fila sicuro in stazione" 
mas se traduz com os músculos das clavículas, cada toque nas teclas da máquina reflete ali"29 (BIANCIARDI, 2016, p. 183).

Em tal contexto, o que dizer da condição privilegiada, à margem do sistema, autônoma e independente? Nas palavras do narrador, atormentado pelos prazos, é evidente que o controle dos próprios tempos e a liberdade de gerenciar a própria vida são um engodo.

Para Marx, já era claro que "[o] reino da liberdade só começa, de fato, onde cessa o trabalho determinado pela necessidade e pela adequação a finalidades externas" (MARX, 1986, p. 273), ao passo que o pleno desenvolvimento das potencialidades humanas é possível apenas fora da esfera da produção material, projetando-nos, na prática, para além da sociedade em que vivemos. O filósofo André Gorz, nas pegadas de Marx, complementa que "o tempo de trabalho e o tempo de viver foram desconectados um do outro; o trabalho, suas ferramentas, seus produtos, adquiriram uma realidade separada do trabalhador" (GORZ, 2007, p. 30). Em La vita agra, os cálculos incessantes, feitos e refeitos, de laudas de tradução, trazem consigo uma lógica perversa, que não só escapa das mãos de quem trabalha, mas o enreda. Assim, o tradutor, de dentro da própria casa, embora contra a vontade, acaba fazendo parte de uma linha de montagem.

Vem acentuar seu sentimento de submissão e controle - não mero sentimento, cabe dizer -, o fato de que, ao assinar um contrato de aluguel, tem seu endereço descoberto pelo fiscal da prefeitura e, em seguida, pelos leituristas do gás e da luz, por vendedores de seguros e de máquinas de escrever elétricas, por cobradores e intimações, que chegam à sua porta, numa interpelação contínua, perturbando sua paz e, o que é pior, prejudicando sua produtividade. Aqui enxergamos a outra face da farsa do progresso em curso: se o indivíduo é alienado na produção, também será no consumo. Surpresa alguma que o personagem seja finalmente enquadrado como cidadão consumidor, e alienado também nessa esfera, ou que suas necessidades e desejos se confundam na névoa de Milão ou nos corredores de um supermercado.

Calvino afirma que um clássico "é um livro que nunca terminou de dizer o que tinha para dizer" (CALVINO, 2009, p. 11), e este parece ser o caso de La vita agra, romance pouco lido, sobretudo fora da Itália, que traz as marcas de sua época, mas se revela contemporâneo e provocativo pela capacidade de antever. Hoje, em tempos de barbárie neoliberal e uberização da economia, não é difícil constatar que Bianciardi acertou o alvo de sua raiva, tanto no olhar crítico mais amplo sobre o progresso, a cidade e o mundo do trabalho, quanto no foco sobre o trabalhador informal, nas vestes de um tradutor da metade do século passado, cada vez mais atual em sua precarização. O objetivo deste texto foi divulgar a obra e seu autor, que, a despeito da distância temporal e espacial em relação ao contexto brasileiro, na condição de crítica contundente a uma realidade que lamentavelmente todos compartilhamos, têm muito a dizer.

\section{Referências}

Adorno, Theodor. Progresso. Tradução de Gabriel Cohn. Lua Nova: Revista de Cultura e Politica. São Paulo, $\mathrm{n}^{\circ}$. 27, 1992, p. 217-236. Disponível em: http://www.scielo.br/scielo.php?script $=$ sci arttext\&pid=S0102-64451992000300011. Acesso em: 13/06/2019

Benjamin, Walter. Passagens. Tradução de Irene Aron; Cleonice Paes Barreto Mourão. Belo Horizonte: UFMG, Imprensa Oficial do Estado de São Paulo, 2007.

29 "non sembra, ma si traduce con quelli [i muscoli sopra le clavicole], ogni colpo sui tasti della macchina si scarica lassù" 
Bianciardi, Luciano. La vita agra. Milano: Giangiacomo Feltrinelli Editore, 2016.

Bruni, Raoul. "La vita agra reloaded. Aggiornamento sulla fortuna di Bianciardi". In: Bruni, Arnaldo et al. (Org.). La vipera che 'l melanese accampa: Luciano Bianciardi, Grosseto e La vita agra. Due giornate di studio per i 50 anni de La vita agra e i 90 anni dalla nascita di Luciano Bianciardi. Milano: ExCogita, 2014.

Calvino, Italo. Por que ler os clássicos. Tradução de Nilson Moulin. São Paulo: Companhia das Letras, 2009.

Corrias, Pino. Vita agra di un anarchico: Luciano Bianciardi a Milano. Milano: Giangiacomo Feltrinelli Editore, 2011.

Gorz, André. Metamorfoses do Trabalho: Crítica da Razão Econômica. Tradução de Ana Montoia. São Paulo: Annablume, 2007.

Hobsbawn, Eric. Era dos Extremos: O breve século XX. 1914-1991. Tradução de Marcos Santarrita. Revisão técnica Maria Célia Paoli. São Paulo: Companhia das Letras, 1997.

Losurdo, Domenico. Hegel e a liberdade dos modernos. Tradução de Ana Maria Chiarini e Diego Silveira Coelho Ferreira. São Paulo: Boitempo, 2019.

Löwy, Michael; Varikas, Eleni. A crítica do progresso em Adorno. Tradução de Régis Castro Andrade. Lua Nova: Revista de Cultura e Política. São Paulo, nº. 27, 1992, p. 201-215. Disponível em: $\quad$ http://www.scielo.br/scielo.php?script=sci arttext\&pid=S010264451992000300010\&lng=en\&nrm=iso\&tlng=pt Acesso em: 13/06/2019

Löwy, Michael. A filosofia da história de Walter Benjamin. Tradução de Gilberto P. Passos. Estudos Avançados, São Paulo, v. 16, nº 45. 2002, p. 199-206.

Löwy, Michael. Walter Benjamin: aviso de incêndio: Uma leitura das teses "sobre o conceito de história". Tradução de Wanda Nogueira Caldeira Brant, [tradução das teses] Jeanne Marie Gagnebin e Marcos Lutz Müller. São Paulo: Boitempo, 2005.

Marchesini, Matteo. "Gaddiano e classicista: Un ritratto di Luciano Bianciardi". In: Bianciardi, Luciana (Org.). Il cattivo profeta: Romanzi, racconti, saggi e diari. Milano: il Saggiatore, 2018.

Marx, Karl. O Capital: Crítica da economia política: o processo global da produção capitalista. Vol. 3, tomo 2. Tradução Regis Barbosa e Flávio R. Kothe. São Paulo: Nova Cultural, 1986.

Pasolini, Pier Paolo. "Il vuoto del potere"" ovvero '1'articolo delle lucciole". Corriere della Sera, 01.02.1975. Disponível em: https://www.corriere.it/speciali/pasolini/potere.html . Acesso em: 13/06/2019

Serino, Gian Paolo. Luciano Bianciardi: Il precario esistenziale. Firenze: Clichy, 2015.

Recebido em: 15 de agosto de 2019

Aceito em: 11 de novembro de 2019

Publicado em: Dezembro de 2019 